\title{
Correction to: Analysis of the quinoa genome reveals conservation and divergence of the flowering pathways
}

\author{
Agnieszka A. Golicz ${ }^{1}$ (D) $\cdot$ Ursula Steinfort $^{2} \cdot$ Hina Arya ${ }^{1} \cdot$ Mohan B. Singh $^{1} \cdot$ Prem L. Bhalla ${ }^{1}$
}

Published online: 18 November 2019

(C) Springer-Verlag GmbH Germany, part of Springer Nature 2019

\section{Correction to: Functional \& Integrative Genomics} https://doi.org/10.1007/s10142-019-00711-1

Owing to an error in the production process the above article was published online with incorrect legends for Figures 5 to 7 . The legend for Fig. 4 was repeated in Fig. 5, causing all the subsequent figure legends to be incorrect. The original article has been corrected.

Publisher's note Springer Nature remains neutral with regard to jurisdictional claims in published maps and institutional affiliations.

The online version of the original article can be found at https://doi.org/ 10.1007/s10142-019-00711-1

Agnieszka A. Golicz

agnieszka.golicz@unimelb.edu.au

$\triangle$ Ursula Steinfort

usteinfo@uc.cl

1 Plant Molecular Biology and Biotechnology Laboratory, Faculty of Veterinary and Agricultural Sciences, University of Melbourne, Parkville, Melbourne, VIC, Australia

2 Facultad de Agronomía e Ingeniería Forestal, Pontificia Universidad Católica de Chile, Santiago, Chile 